\title{
NUMERICAL SIMULATION OF MODIFIED LOW-DENSITY JET PENETRATING SHELL CHARGE
}

\author{
Chang, B. H.; Yin, J. P. ; Cui, Z. Q. \& Liu, T. X. \\ School of Mechatronic Engineering, North University of China, Taiyuan 030051, China \\ E-Mail: changbianhong@nuc.edu.cn, yjp123@nuc.edu.cn (" Corresponding author)
}

\begin{abstract}
In order to solve the problem of inadequate penetration of low-density jet penetrating shell charge, the low-density PTFE are modified by adding a certain fraction of copper powder in the matrix. This treatment helps to increase the material density and jet energy, as well as to improve the static and dynamic mechanical properties of the material. AUTODYN-2D finite element software is used to simulate the process in which the low-density jet forms and penetrates shell charge. The simulation and experiment results show that in comparison to PTFE, the mechanical properties of PTFE/Cu have been significantly improved, and the jet has strong penetration capability. Under the same structural conditions, the penetration diameter of PTFE/Cu jet is about enhanced by $70 \%$ for the panel and $30 \%$ for the back plate compared to that of PTFE jet. As an experimental result, the penetration depth of the main armour by PTFE/Cu jet is enhanced by $5.38 \%$ compared with that of PTFE jet.

(Received, processed and reviewed by the American Society of Science and Engineering.)
\end{abstract}

Key Words: Explosive Mechanics, Numerical Simulation, Finite Element Model, Low-Density Jet

\section{INTRODUCTION}

The emergence of explosive reactive armour (ERA) not only imposes significant impact on traditional anti-tank ammunition, but also promotes the development of new anti-tank ammunition. At present, tandem warhead is generally considered as mature anti-armour ammunition that has been widely applied [1]. Recent research on tandem warhead mainly focuses on the use of low-density liner materials which allows the jets to penetrate but not detonate the ERA-panels. In this way, the ERA-panels can provide necessary channels for the late-stage main jet to successfully pass through the main armour, which enhances the overall penetration capability [2]. Helte and Lundgren [3] empirically tested the penetration capability of precursors of tandem warheads against ERA, and found out that precursors with liners made of alumina powder, aluminium powder and glass could penetrate but not detonate the ERA-panels. Dong et al. [4] used nonlinear dynamic analysis of AUTODYN-2D to carry out simulation test in which PTFE, nylon, resin, glass and other low-density materials were used, and the jet could penetrate but not detonate the ERA-panels with a high-velocity collision. In their simulation, the ERA-panels consisted of thick steel plates sandwiched between several layers of B high-explosive.

However, the inadequate penetration capability of formed jet made of low-density liner materials could severely affect the penetration efficiency of shell charges. Therefore, the modification of low-density liner materials is necessary and urgent. By adding a certain mass fraction of copper, aluminium or other materials, it is possible to increase the overall density and jet EFP energy, as well as to improve the static and dynamic mechanical properties of the material. Rae and Brown [5] have conducted previous research on the performance of PTFE in compression and tension loads. Samples of DuPont 7A and 7C Teflon (PTFE, polytetrafluoroethylene) were tested in tension at strain-rates between $2 \times 10^{-4}$ and $0.1 \mathrm{~s}^{-1}$ and temperatures between $-50^{\circ} \mathrm{C}$ and $150^{\circ} \mathrm{C}$. Additionally, using a Hopkinson bar, a temperature series was undertaken in tension between $-50{ }^{\circ} \mathrm{C}$ and $23{ }^{\circ} \mathrm{C}$ at a strain rate of $800 \mathrm{~s}^{-1}$. Results indicated that both temperature and strain-rate had great influence on the tensile mechanical 
properties of PTFE. Further high strain rate data on Teflon versus temperature was published by Walley et al. [6]. Khan and Zhang [7] published some room temperature strain-rate sensitivity data for PTFE between $10^{-4}$ and $1 \mathrm{~s}^{-1}$. Ye et al. [8] have comprehensively researched the mechanical properties and friction performances of modified PTFE filled with bronze powder of various types, shapes and sizes. The results indicated that PTFE composites with $40 \%$ bronze have better mechanical properties and good anti-wear performances. Gutsev et al. [9] study the effect of silicon dioxide and PTFE additives on NiP coating performance under dry (unlubricated) conditions in unidirectional and reciprocating sliding modes in Ballon-Flat configuration. Zhang et al. [10] studied the impact of $\mathrm{Cu}, \mathrm{Pb}$ and $\mathrm{Ni}$ on the friction and wear properties of PTFE-based composites. Martins et al. [11] study the mechanical behaviour of a polytetrafluoroethylene (PTFE) polymer, with and without inclusions of silica particles. The results of Conte and Igartua [12] research suggest that a comparative study between different kinds of filled PTFEs is proposed to have a map of PTFE materials to be used depending by the tribological application. Xie et al. [13] have provided numerical analyses to explore the effects of the addition of copper powder into PTFE composites on thermal conductivity. Results indicated that with an increasing amount of copper content in the filling, the thermal conductivity of the PTFE composite can be significantly improved. Sorensen [14] presents the Al/PTFE experimental results, using the nylon, aluminium, and steel cylindrical projectile data for comparison to determine if the addition of the reactive material changed the projectile/target interaction. The objective of the present work is to understand the penetration capability of low-density jet under the influence of high-velocity impact loading, and to provide reference information for the improvement of the penetration capability and destroy efficiency of low-density jet against shell charge. The process of the formation of low-density jet based on modified PTFE/Cu liner materials and the impact response of shell charge were numerically studied.

\section{THE ESTABLISHMENT OF NUMERICAL SIMULATION MODEL OF MODIFIED LOW-DENSITY JET}

\subsection{The structure of shaped charge and the establishment of the finite element model}

The structure of shaped charge includes conic cover of uniform liner thickness, which is used to treat rounded corners for safety reasons. The low-density material conical liner which is made of $38.5 \% \mathrm{Cu}$ powders and $61.5 \%$ PTFE is made by filling modification process. The process is: mixing $\mathrm{Cu}$ powders with lubricant. $\mathrm{Cu}$ powder lubricant suspension is formed. Then the suspension is added to the PTFE to make the modified PTFE material. The initialization parameters are: liner cone angle is $50^{\circ}$, the diameter is $40 \mathrm{~mm}$, and the charge height is $40 \mathrm{~mm}$. Truegrid software was used to establish a finite element model that could reflect the modified low-density liner shaped charge as shown in Fig. 1. The model consists of three components, namely, a modified low-density liner, explosives, and the flow of air. AUTODYN-2D finite element software is then used to simulate numerically the process when the jet is formed from modified low-density liner under the influence of blast loading. Meanwhile, Euler algorithm, a representative of the unit algorithm, is used to simulate the detonation process of the explosives, the crush of the liner, and the formation of the modified low-density jet. The Euler grid is sufficient to cover the detonation products and the formation space of the low-density jet. Solid164 eight-node hexahedral elements are chosen to reflect grid cell structure, and 1/4 model is established according to the symmetrical structure of the charge in order to save computing time. 


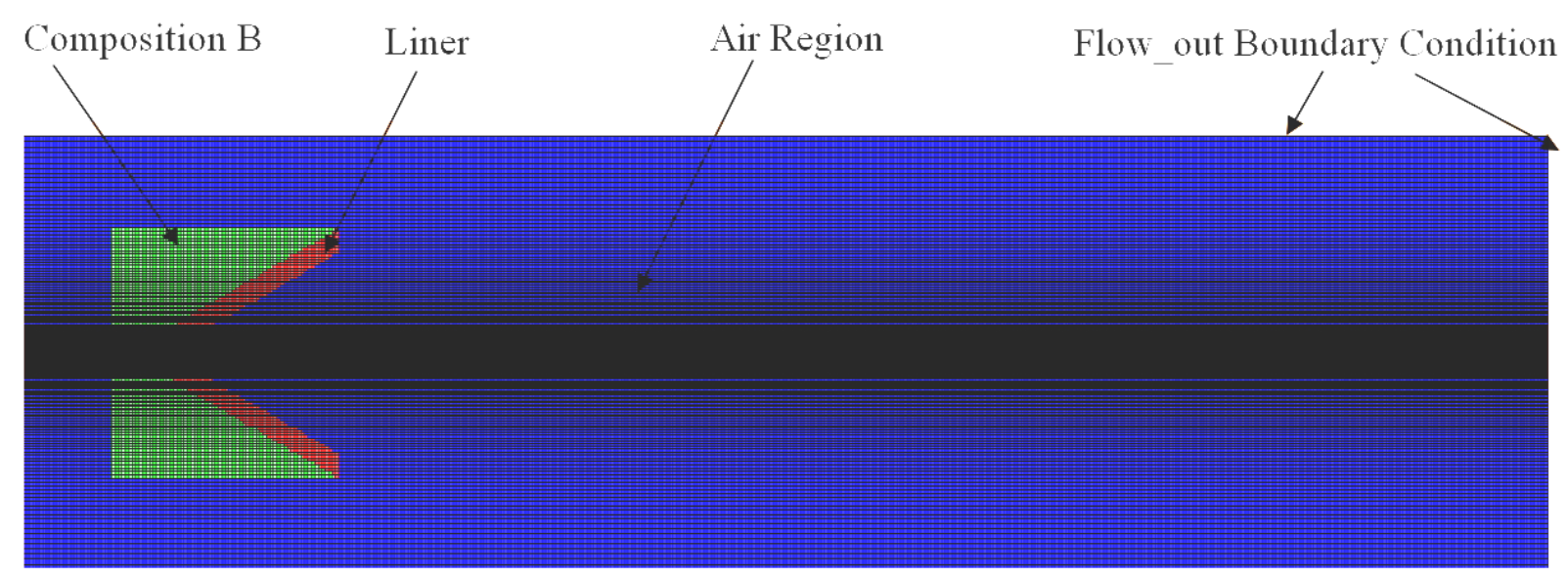

Figure 1: The establishment of the finite element model of modified low-density liner.

\subsection{Material models and state equation}

In the numerical simulation, Composition $\mathrm{B}$ were chosen as the main charge, HIGH_EXPLOSIVE_BURN was selected as the material model of high energy explosives, and JWL was used for the state equation. JWL accurately describes the pressure, volume, and energetic characteristics of detonation gas products during the explosive-driven process, which is expressed as:

$$
p=A\left(1-\frac{\omega}{R_{1} V}\right) e^{-R_{1} V}+B\left(1-\frac{\omega}{R_{2} V}\right) e^{-R_{2} V}+\frac{\omega E_{0}}{V}
$$

In the equation, $A, B, R_{1}, R_{2}$ and $\omega$ represent the input parameters, $E_{0}$ represents the initial ratio of the internal energy, and $V$ represents the initial relative volume of the detonation products. The values of the main parameters of Composition $B$ are: $\rho_{0}=1.7 \times 10^{-3} \mathrm{~g} / \mathrm{cm}^{3}$, $D=8400 \mathrm{~m} / \mathrm{s}, p_{C J}=30 \mathrm{GPa}, E_{0}=10.0 \mathrm{GPa}$. The materials of liner include PTFE and modified PTFE (PTFE/Cu). Under blast loading conditions, the performance of the materials can be considered to follow the category of ideal fluid elastoplastic model. Therefore, von Mises yield criterion, instantaneous failure criterion, and shock equation of state were used to describe the dynamic response behaviour of liner materials under the influence of blast loading, and to calculate large deformation status under high strain rate $\left(>10^{5}\right)$ conditions. Material parameters of the two types of liner are shown in Table I.

Table I: The basic parameters of low-density liner materials.

\begin{tabular}{|c|c|c|c|c|c|c|}
\hline Parameters & $\rho\left(\mathrm{g} / \mathrm{cm}^{3}\right)$ & $G(\mathrm{MPa})$ & $\sigma_{Y}(\mathrm{MPa})$ & $\begin{array}{c}\text { Gruneisen } \\
\text { coefficient }\end{array}$ & $C_{\mathbf{1}}(\mathrm{km} / \mathrm{s})$ & $S_{1}$ \\
\hline PTFE & 2.16 & 2330 & 50 & 0.9 & 1.34 & 1.93 \\
\hline PTFE $/ \mathrm{Cu}$ & 3.05 & 1370 & 46 & 0.9 & 1.34 & 1.93 \\
\hline
\end{tabular}

During the calculation process, MAT_NULL is used to calculate air materials. The liner polynomial state equation was described by EOS_LINER_POLYNOMIAL. The main parameters include: density $\rho_{0}=1.293 \times 10^{-3} \mathrm{~g} / \mathrm{cm}^{3}$, sound velocity $C=340 \mathrm{~m} / \mathrm{s}$ and initial relative volume $V_{0}=1.0$. 


\section{NUMERICAL SIMULATION OF THE FORMATION OF MODIFIED LOW-DENSITY JET}

\subsection{Numerical simulation and analysis of the formation of modified low-density jet}

Fig. 2 shows the process of centre detonating manner and the formation of modified lowdensity jet. It can be seen that four main steps are included in the formation process, namely, the detonation of shaped charge, the crush of modified low-density liner, the initial formation of modified low-density jet, and the extension of formed jet, with such four steps representing four-dimensional axisymmetric problems. Under the influence of blast loading, the liner displays accelerating motion towards the axis of symmetry until the collision occurs and highvelocity jet is formed inside the liner, whereas rod-shaped projectile with low velocity is formed around the boundary of the liner. After instantaneous detonation process of explosives, jet head is formed. As the detonation wave on the liner is continuous, the liner is under constant pressure, which leads to continuous inflow of jet mass and energy. As a result, jet head speeds up to the maximum velocity. As jet mass and energy decreases, jet head slows down along the longitudinal direction. Due to the existence of the velocity gradient inside the jet, it is continuously stretched during the motion process.

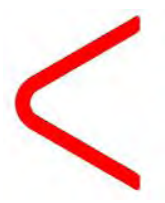

$0 \mu \mathrm{s}$

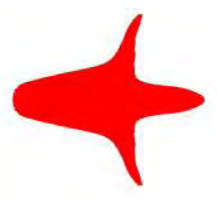

$10 \mu \mathrm{s}$

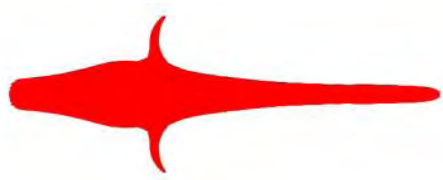

$20 \mu \mathrm{s}$

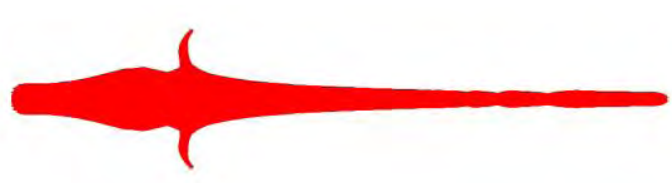

$30 \mu \mathrm{s}$

Figure 2: Numerical simulation of the formation of PTFE/Cu at different time.

Through structural optimization and numerical simulation of the jet from modified lowdensity liner materials, scenarios of liner types with different liner thicknesses or cone angles are discussed. With the liner thickness of 2, 2.5, 3, 3.5 and $4 \mathrm{~mm}$ and corresponding cone angle of $50^{\circ}, 55^{\circ}, 60^{\circ}, 65^{\circ}$ and $70^{\circ}$, respectively, the changing patterns of the head velocity and associated cone of the modified low-density jet could be obtained. Fig. 3 shows the head velocity curve of low-density jet when different types of liners are used with liner thickness of $3 \mathrm{~mm}$. It can be seen from this figure that as cone angle increases, the head velocity of modified low-density jet decreases.

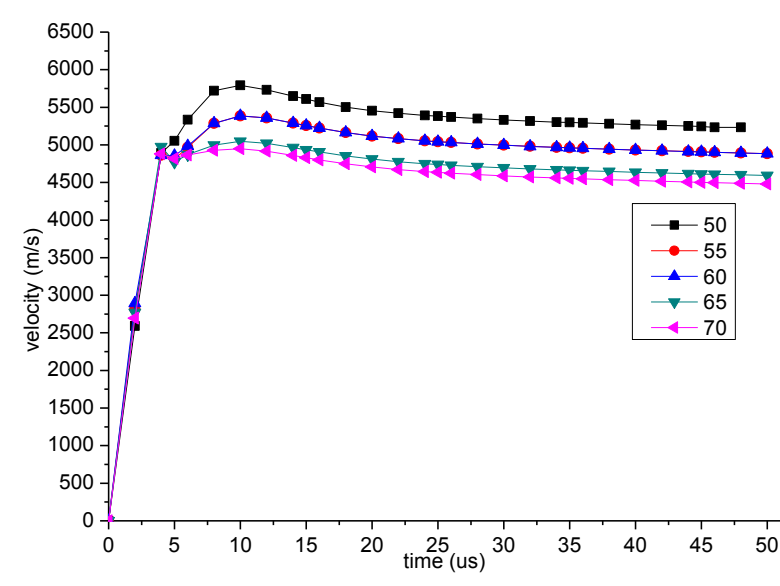

Figure 3: The head velocity curve of low-density jet when different liner cone angles.

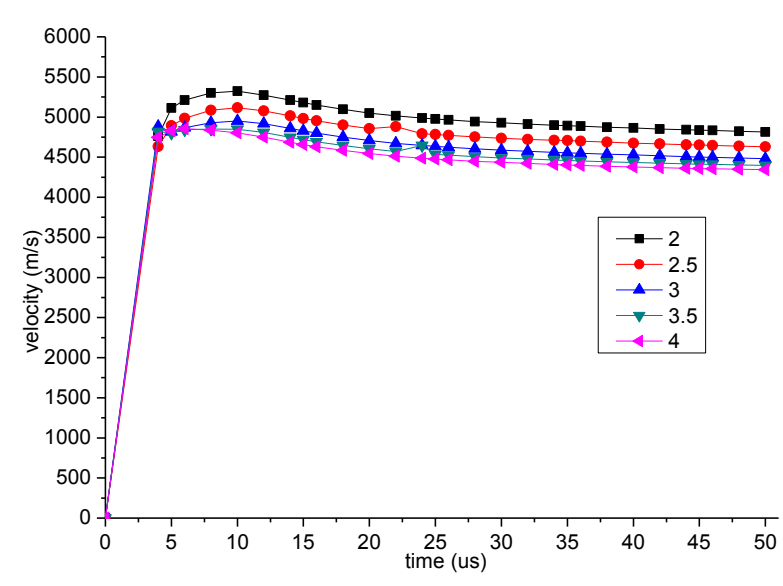

Figure 4: The head velocity curve of low-density jet when different liner thicknesses. 
Fig. 4 shows the head velocity curve of low-density jet when different liner thicknesses are used with liner cone angle $50^{\circ}$. It can be seen from this figure that as thickness of the liner increases, the head velocity of modified low-density jet decreases. Finally, the optimized structure is achieved when liner thickness is $3 \mathrm{~mm}$ and cone angle is $55^{\circ}$ by numerical simulation of AUTODYN-2D software.

\subsection{Comparison between the performance of modified and non-modified low-density jet}

From numerical results, it can be seen that the low-density jet based on PTFE/Cu or PTFE liner and the length of associated rod-shaped projectile gradually increase over time. At the time of $2 \mu \mathrm{s}$, explosive detonation reaches the top of liner. At $10 \mu \mathrm{s}$, the closure process is along the central axis as different types of liners are crushed. At $20 \mu \mathrm{s}$, the basic form of jet has formed. Also, jet head is formed after the collision events occur at the symmetry plane. Due to the existence of a velocity gradient between jet head and jet tail, the jet is gradually stretched over time. Shaped charge with the same structure displays a similar pattern under the influence of blast waves. Due to the density difference (PTFE $<$ PTFE/Cu), the formed jet is longer for PTFE liner than that for PTFE/Cu liner. In addition, the head velocity of jet is higher for PTFE liner than that for PTFE/Cu liner. The density difference results in a higher energy level for $\mathrm{PTFE} / \mathrm{Cu}$ liner. Therefore, the $\mathrm{PTFE} / \mathrm{Cu}$ liner has a stronger penetration capability.

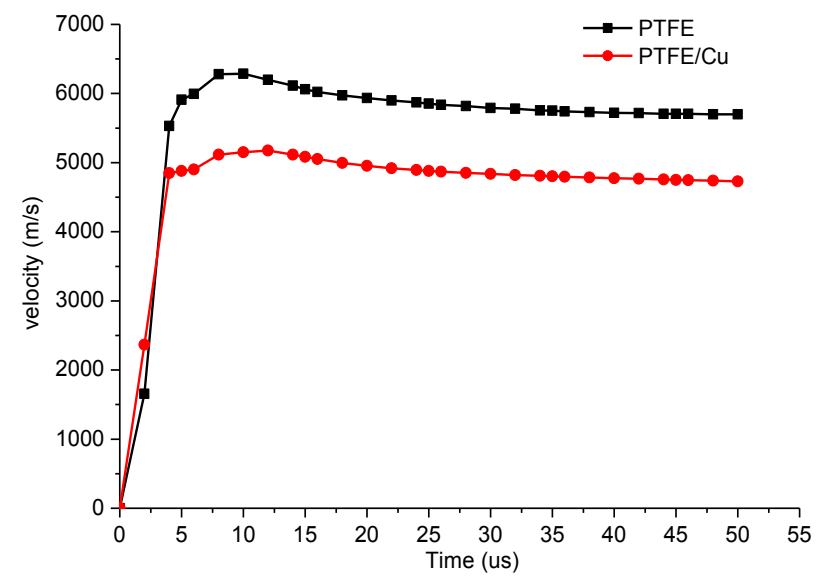

Figure 5: A comparison graph of the head velocity of jet for two different materials.

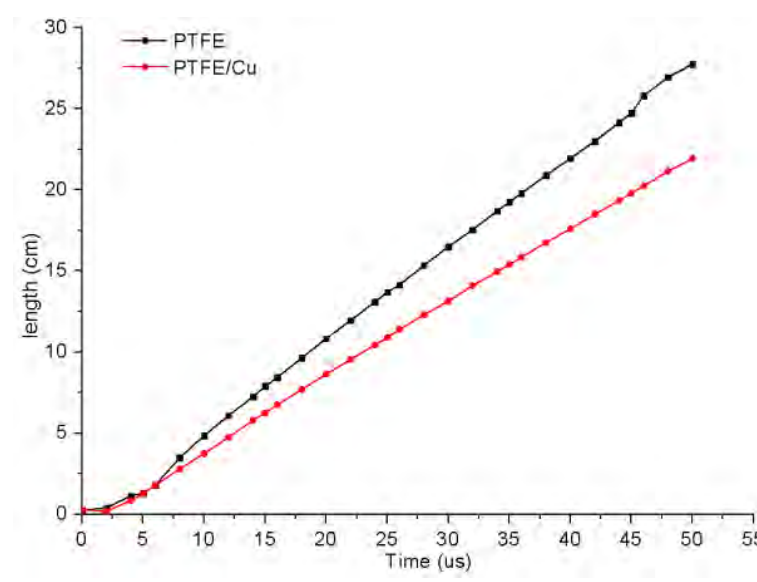

Figure 6: A comparison graph of jet length over time for two different materials.

Fig. 5 shows the head velocity of jet when two different materials are used. It can be noted that when the influence of blast loading is directly imposed on shaped charge liner, the latter is crushed and jet head is immediately formed. At $8 \mu \mathrm{s}$, the head velocity of PTFE jet reaches a maximum velocity of $6278 \mathrm{~m} / \mathrm{s}$. By contrast, the head velocity of PTFE/Cu jet reaches a maximum velocity of $5176 \mathrm{~m} / \mathrm{s}$ at $12 \mu \mathrm{s}$. After that the jet is continuously stretched, and a gradient of velocity exists between jet head and rod-shaped projectile. A high level of velocity remains during the penetration process and there is an evident penetration effect. The stretch process of low-density jet is compared in Fig. 6 for the two materials. Since the compressive strength is higher for PTFE/Cu than that for PTFE, a longer jet is formed for PTFE under the influence of blast loading. The stretching rate of PTFE/Cu jet is smaller than that of PTFE jet. At $50 \mu \mathrm{s}$, the jet length of PTFE/Cu jet is $21.95 \mathrm{~cm}$ while the length of PTFE jet is $27.75 \mathrm{~cm}$, the latter being $20.9 \%$ longer than the former. 


\section{THE FINITE ELEMENT MODEL OF MODIFIED LOW-DENSITY JET PENETRATING SHELL CHARGE}

\subsection{The structure of shaped charge penetrating shell and the finite element model}

The structure of shaped charge is shown in Fig. 7, for which conic cover with same liner thickness is applied, and the treatment of rounded corners is done for safety reasons. Liner cone angle $\alpha$, the diameter is $10 \mathrm{~mm}$, and the charge height is as large as the diameter. A typical structure is used to represent the process of shell charge, namely, $2 \mathrm{~mm}$ for panel thickness, $4 \mathrm{~mm}$ for the thickness of COMPBJJ1B explosive, and $2 \mathrm{~mm}$ for the thickness of back plate. With the actual structure taken into account, a $3 \mathrm{~mm}$-thick shield plate is placed in front of the panel. The materials of both shell charge and shield plate are made of $30 \mathrm{GrMnSi}$. The linear equation of state, Von Mises intensity model and Plastic strain failure model are implemented.

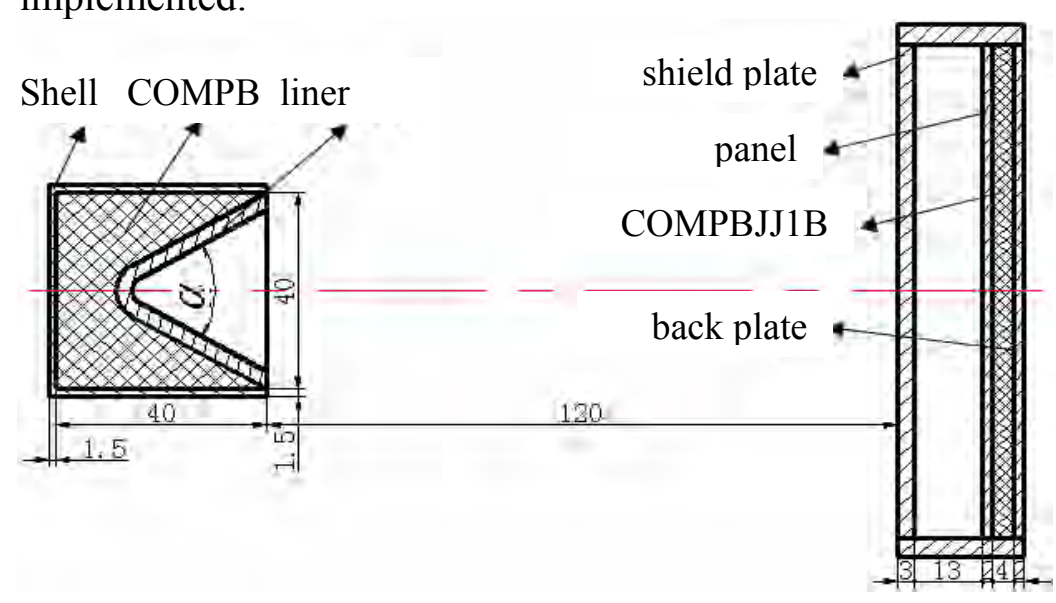

Figure 7: The structure of shaped charge penetrating shell charge.

The explosion of shaped charge, the process of crush and closure, and the formation of jet under the influence of blast loading fall into large deformation category. In general, EULER algorithm is commonly used to deal with large deformation issues of materials. Because the model has the specific structure that can be evenly divided along the axis of symmetry, a $1 / 2$ 2-dimensional model can be established for numerical simulation purpose. Here the influence of shell charge can be neglected, and the finite element model after mirror symmetry treatment is shown in Fig. 8.

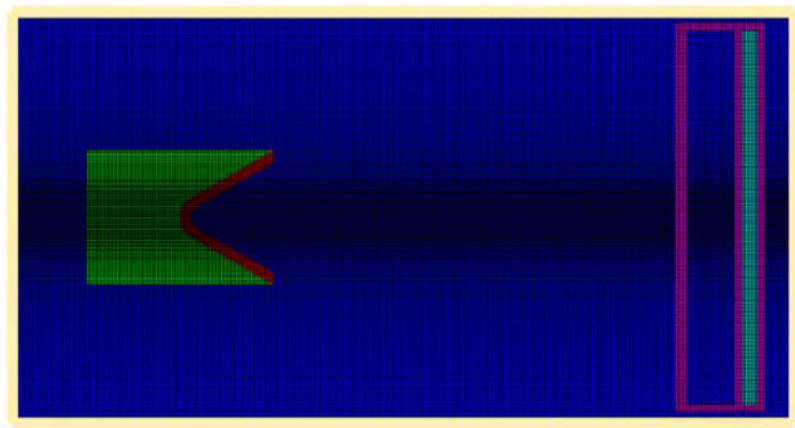

Figure 8: The finite model of shaped charge penetrating shell charge.

\subsection{Material model and the equation of state}

In the numerical simulation, Composition B was chosen as the main charge, COMPBJJ1 was chosen as the shell charge, and Lee-Tarver model was chosen as the equation of state that 
reflects the process of ignition and growth. Specifically, Lee-Tarver model can be expressed as:

$$
\partial F / \partial t=I(1-F)^{b}(\mu-a)^{x}+G_{1}(1-F)^{c} F^{d} p^{y}+G_{2}(1-F)^{e} F^{g} p^{z}
$$

All parameters of the equation are shown in Table II.

Table II: Lee-Tarver parameters of COMPBJJ1B explosives.

\begin{tabular}{|c|c|c|c|c|c|c|c|}
\hline$I\left(\mu \mathrm{s}^{-1}\right)$ & $a$ & $b$ & $c$ & $d$ & $e$ & $g$ & $x$ \\
\hline 44 & 0.01 & 0.222 & 0.222 & 0.667 & 0 & 0 & 4 \\
\hline$y$ & $z$ & $G_{1}$ & $G_{2}$ & $F_{\text {ig max }}$ & $F_{G 1 \max }$ & $F_{G 2 \min }$ & \\
\hline 2 & 0 & 414 & 0 & 0.3 & 1 & 1 & \\
\hline
\end{tabular}

\section{NUMERICAL SIMULATION OF MODIFIED LOW-DENSITY JET PENETRATING SHELL CHARGE AND MAIN ARMOUR}

\subsection{Numerical simulation of modified low-density jet penetrating shell charge}

Fig. 9 shows the process of centre detonation in which the modified low-density jet influences shell charge. At $29 \mu \mathrm{s}$, the jet starts to contact the shield plate, which initiates the penetration process. Because PTFE/Cu has a relatively large density, when the jet head penetrates the shield plate, the produced energy is large enough to penetrate the entire shield plate. When holes are made in the shield plate, the invasion process of jet continues. At $35 \mu \mathrm{s}$, the penetration process of the panel starts. Due to the existence of a velocity gradient of PTFE/Cu jet, jet diameter of the back position is larger, and the bore diameter of both the panel side and the back plate is relatively large for the entire shell charge.

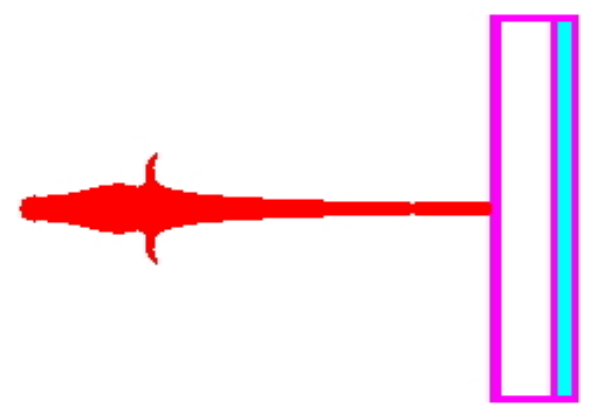

a) Penetration of the shield plate at $29 \mu \mathrm{s}$

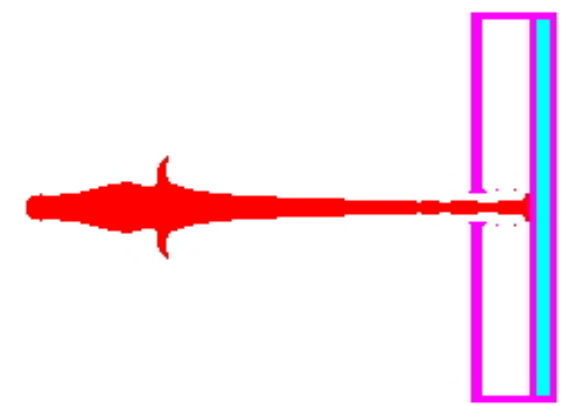

c) Penetration of the panel at $35 \mu \mathrm{s}$

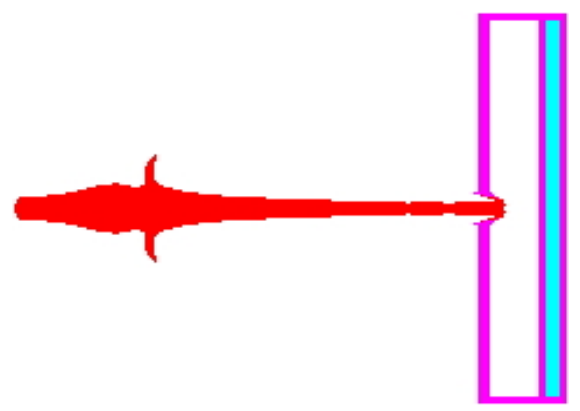

b) Perforation through the shield plate at $32 \mu \mathrm{s}$

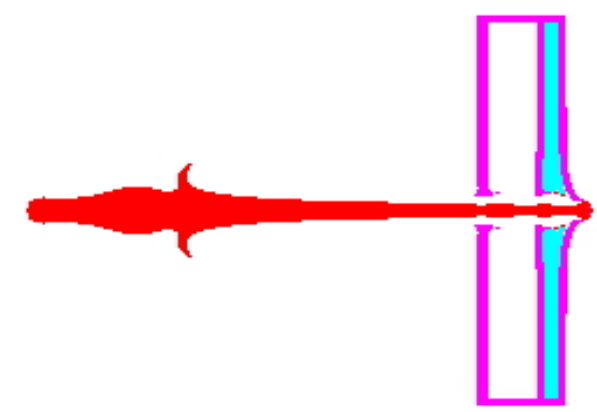

d) Perforation through the back plate at $43 \mu \mathrm{s}$

Figure 9: Numeric simulation of PTFE/Cu jet penetrating shell charge. 
Fig. 10 gives the reaction nephogram of the impact of PTFE/Cu jet on shell charge. Since $\mathrm{PTFE} / \mathrm{Cu}$ jet has a high level of energy, the reaction of the explosion process is strong, although it doesn't lead to detonation. Instead, it hinders the movement of the jet and initiates a deflagration. Since the diameter of PTFE/Cu jet head is relatively large, the jet displays consistency, and therefore causes large-diameter perforations. Therefore, initiation pressure of explosive is affected by PTFE jet and PTFE/Cu jet, numerical simulation shows initiation pressure of PTFE jet against explosive is $16.624 \mathrm{GPa}$, and that of PTFE/Cu jet is $15.468 \mathrm{GPa}$.

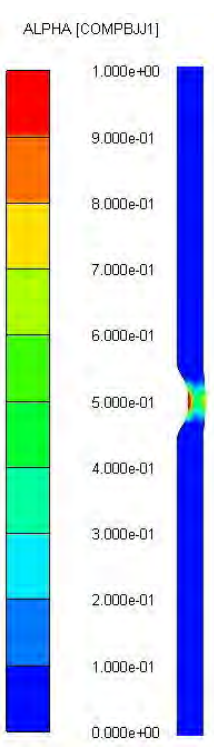

$35 \mu \mathrm{s}$

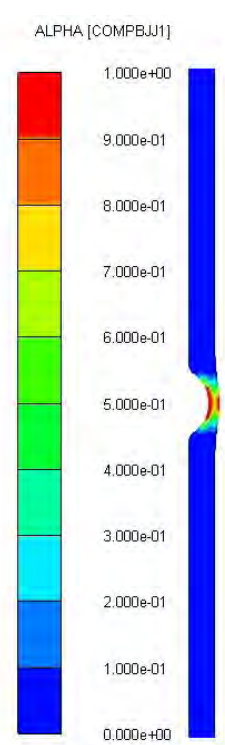

$38 \mu \mathrm{s}$

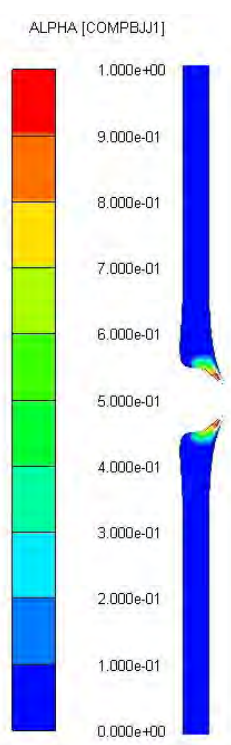

$41 \mu \mathrm{s}$

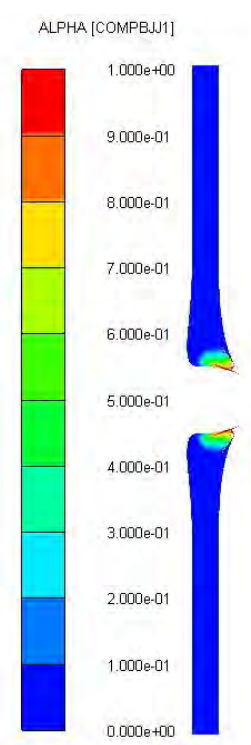

$44 \mu \mathrm{s}$

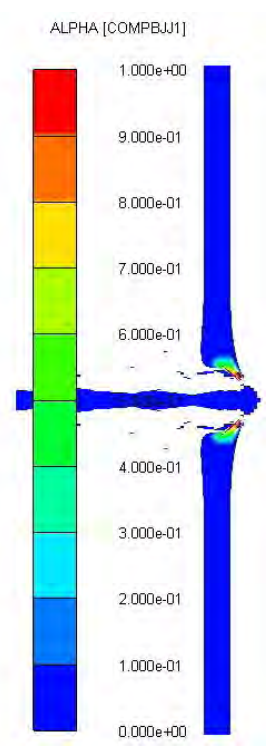

$47 \mu \mathrm{s}$

Figure 10: The reaction nephogram of PTFE/Cu jet penetrating shell charge.

Numerical simulation shows that when PTFE jet penetrates the shell charge, the head diameter is $3.3 \mathrm{~mm}$. When the penetration process ends, the diameter of the shield plate is $4.87 \times 2=9.74 \mathrm{~mm}$, the bore diameter of the panel is $2.52 \times 2=5.04 \mathrm{~mm}$, and the diameter of the back plate is $3.10 \times 2=6.20 \mathrm{~mm}$. By contrast, when $\mathrm{PTFE} / \mathrm{Cu}$ jet penetrates the shell charge, the head diameter is $2.7 \mathrm{~mm}$. When the penetration process ends, the diameter of the shield plate is $3.75 \times 2=7.50 \mathrm{~mm}$, the bore diameter of the panel is $4.30 \times 2=8.60 \mathrm{~mm}$, and the diameter of the back plate is $4.00 \times 2=8.00 \mathrm{~mm}$. It can be seen from the graph that through the entire penetration process, PTFE/Cu jet shows a weaker penetration capability than PTFE jet, because the former has a smaller initial head diameter than the latter. However, PTFE jet head can get accumulated in the target when it starts to penetrates the shield plate due to its low level of density. As a result, large-diameter perforations are produced. Because late-stage PTFE jet displays shrinkage phenomenon, its head diameter starts to decrease gradually. Because PTFE/Cu jet has a higher level of energy than PTFE, the perforation diameter of the panel for PTFE/Cu jet is $70.6 \%$ higher than that of PTFE jet; the perforation diameter of the back plate for PTFE/Cu jet is $29.0 \%$ higher than that of PTFE jet.

\subsection{Numerical simulation of modified low-density jet penetrating the main armour}

In order to better compare the damage capability between PTFE/Cu and PTFE, numerical simulation was performed on the process of the jet penetration into the main armour after successfully penetrates shell charge. The aim is to further analyse the residual penetration effect of the low-density jet formed from these two materials. The armour is made of 4340 steel with a thickness of $10 \mathrm{~cm}$. Johnson-Cook intensity model is used, with associated parameters shown in Table III. 
Table III: Material parameters of the main armour.

\begin{tabular}{|l|c|c|c|c|c|c|c|}
\hline Parameters & $\begin{array}{c}\rho \\
\left(\mathrm{g} / \mathrm{cm}^{3}\right)\end{array}$ & $G(\mathrm{GPa})$ & $\sigma_{Y}(\mathrm{MPa})$ & $\begin{array}{c}\text { Harding } \\
\text { constant } \\
(\mathrm{MPa})\end{array}$ & $\begin{array}{c}\text { Harding } \\
\text { exponent }\end{array}$ & $\begin{array}{c}\text { Strain } \\
\text { rate } \\
\text { constant }\end{array}$ & $\begin{array}{c}\text { Thermal } \\
\text { softening } \\
\text { exponent }\end{array}$ \\
\hline STEEL 4340 & 7.83 & 81.8 & 792 & 510 & 0.26 & 0.014 & 1.03 \\
\hline
\end{tabular}



$60 \mu \mathrm{s}$

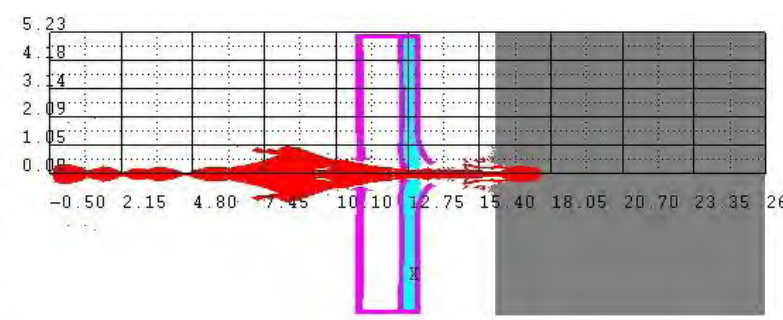

$90 \mu \mathrm{s}$

a) Numeric simulation of PTFE jet penetrating the main armour

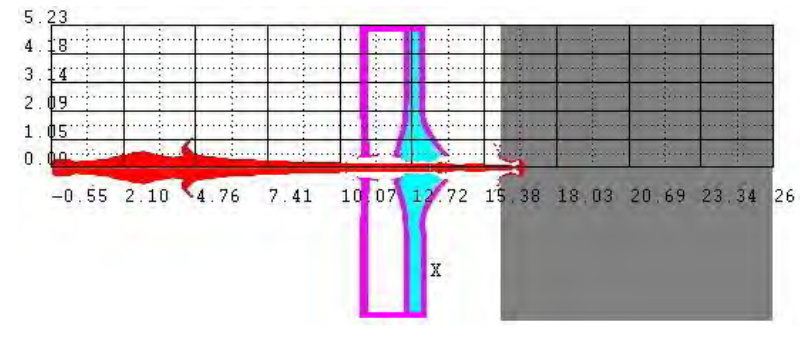

$60 \mu \mathrm{s}$

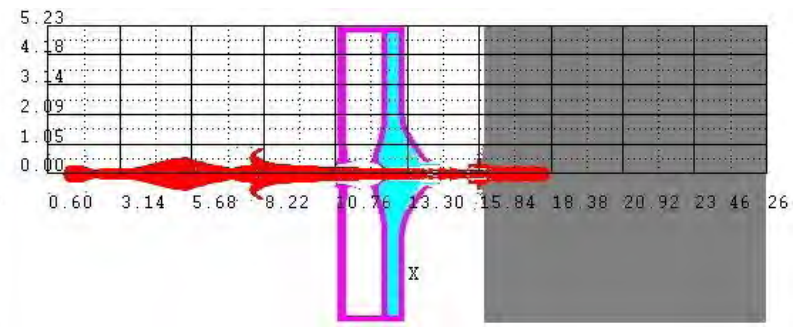

$100 \mu \mathrm{s}$

b) Numeric simulation of PTFE/Cu jet penetrating the main armour

Figure 11: Comparison of residual destroy effect of low-density jet after reactive armour is penetrated.

It can be seen from the simulation results (shown in Fig. 11) that as the penetration process continues, PTFE/Cu jet displays a higher level of consistency than that of PTFE jet, and the former has a higher level of material utilization rate than the latter. Numerical simulation also shows that when PTFE jet penetrates the shell charge, the jet velocity is 4220 $\mathrm{m} / \mathrm{s}$, the head diameter is $2.4 \mathrm{~mm}$, and the ultimate penetration depth of the main armour is $17.5 \mathrm{~mm}$, with perforation diameter of $5.76 \mathrm{~mm}$. By contrast, when PTFE/Cu jet penetrates into shell charge, the jet velocity is $3825 \mathrm{~m} / \mathrm{s}$, the head diameter is $2.1 \mathrm{~mm}$, and the ultimate penetration depth of the main armour is $18.4 \mathrm{~mm}$, with perforation diameter of $4.86 \mathrm{~mm}$. Therefore, PTFE/Cu jet has a better penetration capability than that of PTFE (the former is $5.14 \%$ higher than the latter), although $\mathrm{PTFE} / \mathrm{Cu}$ jet has a smaller perforation diameter.

\section{EXPERIMENT VERIFICATION OF MODIFIED LOW-DENSITY JET PENETRATING SHELL CHARGE AND MAIN ARMOUR}

The experimental device is machined based on the size of the finite element model of shaped charge penetrating on shell charge and main armour, experiment arrangement is shown in Fig. 12. The experimental study is conducted to verify the penetration of PTFE/Cu jet and PTFE jet impact on shell charge or main armour. 


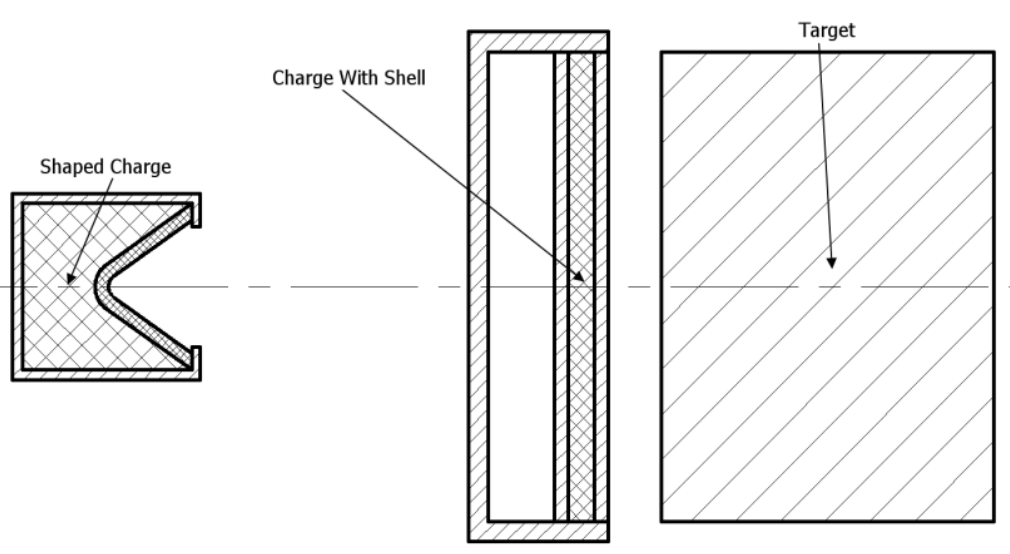

Figure 12: The experimental arrangement of modified jet penetrating shell charge and main armour.

Fig. 13 shows the experimental results PTFE/Cu jet and PTFE jet penetrating shell charge. When the penetration process of PTFE jet ends, the diameter of the shield plate is $4.76 \times 2=9.52 \mathrm{~mm}$, the bore diameter of the panel is $2.46 \times 2=4.92 \mathrm{~mm}$, and the diameter of the back plate is $3.02 \times 2=6.02 \mathrm{~mm}$. By contrast, after PTFE $/ \mathrm{Cu}$ jet penetrates the shell charge, the diameter of the shield plate is $3.86 \times 2=7.72 \mathrm{~mm}$, the bore diameter of the panel is $4.21 \times 2=8.42 \mathrm{~mm}$, and the diameter of the back plate is $4.05 \times 2=7.91 \mathrm{~mm}$. The experimental results show that the perforation diameter of the panel for $\mathrm{PTFE} / \mathrm{Cu}$ jet is $71.1 \%$ higher than that of PTFE jet; the perforation diameter of the back plate for PTFE/Cu jet is $31.4 \%$ higher than that of PTFE jet. It can be seen that the experimental results are consistent with the results of numerical simulation.
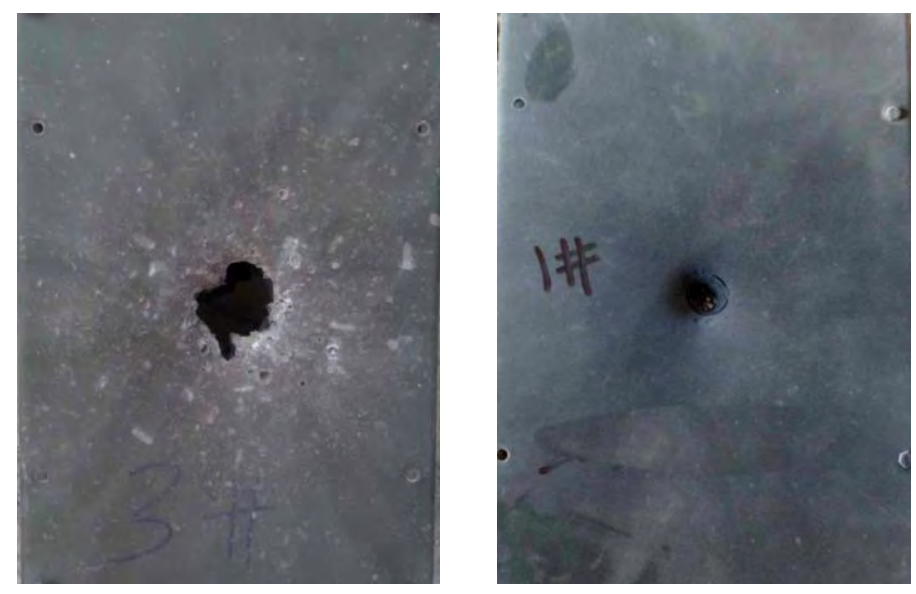

Figure 13: The experimental results PTFE jet and PTFE/Cu jet penetrating shell charge.


Figure 14: The experimental results PTFE jet and PTFE/Cu jet penetrating main armour. 
Fig. 14 shows the experimental results PTFE/Cu jet and PTFE jet penetrating main armour. When the penetration process of PTFE jet ends; the ultimate penetration depth of the main armour is $18.6 \mathrm{~mm}$, with perforation diameter of $6.08 \mathrm{~mm}$. By contrast, when PTFE/Cu jet penetrates into main armour and the ultimate penetration depth of the main armour is 19.6 $\mathrm{mm}(5.38 \%$ higher than the former), with perforation diameter of $5.12 \mathrm{~mm}$. Therefore, $\mathrm{PTFE} / \mathrm{Cu}$ jet has a better penetration capability than that of PTFE. It can be seen that the experimental results are consistent with the results of numerical simulation.

\section{CONCLUSION}

AUTODYN-2D finite element model is adopted to numerically simulate the formation of jet when PTFE/Cu liner has different cone angles and liner thicknesses. The results show that the optimized structure is achieved when liner thickness is $3 \mathrm{~mm}$ and cone angel is $55^{\circ}$. At $30 \mu \mathrm{s}$, head velocity of PTFE/Cu jet is $4996 \mathrm{~m} / \mathrm{s}$, with head diameter of $3.2 \mathrm{~mm}$. According to numerical simulation and experimental verification, When $\mathrm{PTFE} / \mathrm{Cu}$ is used for warhead design as the precursor liner of tandem warhead, it shows good destroy efficiency against shell charge. The perforation efficiency is about enhanced by $70 \%$ for the panel and $30 \%$ for the back plate when the material is changed from PTFE to PTFE/Cu by means of the simulation and experiment. It can be seen that the experimental results are consistent with the results of numerical simulation. As an experimental results, after PTFE/Cu jet penetrating shell charge, its penetration depth of the main armour can be enhanced by $5.38 \%$ compared to the scenario when PTFE jet is used. Therefore, the modified low-density jet which was designed in this paper have been significantly improved penetration energy, broadened pore size, and increased damage performance in the absence of the charge shell explosion.

\section{ACKNOWLEDGEMENT}

The authors would like to acknowledge the financial support from Project supported by the National Natural Science Foundation of China under Grant number 11572291 and 11402027.

\section{REFERENCES}

[1] Lang, M. J.; Xu, X. H. (2002). Calculation and test on flame-proof time of multistage-series shaped charge, Journal of Nanjing University of Science and Technology, Vol. 26, No. 6, 625628, doi:10.14177/j.cnki.32-1397n.2002.06.015

[2] Li, H. L.; Zhu, L. N.; Xie, S. J. (2012). Modified Polytetrafluoroethylene and its application, Hydraulics Pneumatics \& Seals, Vol. 32, No. 6, 4-8, doi:10.3969/j.issn.1008-0813.2012.06.002

[3] Helte, A.; Lundgren, J. (2011). Non-initiating precursor charge technology against era, $26^{\text {th }}$ International Symposium on Ballistics, Miami, Florida, 313-318

[4] Dong, F. D; Wang, Z. J.; Yin, J. P.; Gao, S. P. (2013). Numerical simulation on initiating value of low density jet impacting explosive with shell, Ordnance Material Science and Engineering, Vol. 36, No. 4, 53-55, doi:10.14024/j.cnki.1004-244x.2013.04.010

[5] Rae, P. J.; Brown, E. N. (2005). The properties of poly(tetrafluoroethylene) (PTFE) in tension, Polymer, Vol 46, No. 19, 8128-8140, doi:10.1016/j.polymer.2005.06.120

[6] Walley, S. M.; Field, J. E.; Safford, N. A. (1991). A comparison of the high strain rate behaviour in compression of polymers at $300 \mathrm{~K}$ and 100K, Journal de Physique IV France, Vol. 1, No. C3, 185-190, doi:10.1051/jp4:1991324

[7] Khan, A; Zhang, H. (2001). Finite deformation of a polymer: experiments and modeling, International Journal of Plasticity, Vol. 17, No. 9, 1167-1188, doi: 10.1016/S07496419(00)00073-5

[8] Ye, S. J.; Fan, Q.; Deng, L. Y.; Wang, Y. (2010). Mechanical and tribological properties of copper filled PTFE composites, Lubrication Engineering, Vol. 35, No. 9, 60-64, doi: $10.3969 /$ j.issn.0254-0150.2010.09.014 
[9] Gutsev, D.; Antonov, M.; Hussainova, I; Grigoriev, A. Ya. (2013). Effect of $\mathrm{SiO}_{2}$ and PTFE additives on dry sliding of NiP electroless coating, Tribology International, Vol. 65, 295-302, doi:10.1016/j.triboint.2012.12.012

[10] Zhang, Z. Z.; Xue, Q. J.; Shen, W. C.; Liu, W. M. (1999). Friction and wear properties of PTFE composites filled by metal, Polymer Materials Science \& Engineering, Vol. 15, No. 1, 68-73, doi: 10.3321/j.issn:1000-7555.1999.01.019

[11] Martins, S. A.; Dias, F. W; Nunes, L. S.; Borges, L. A.; D'Almeida, J. R. (2011). Mechanical characterization of silica reinforced-PTFE matrix composites, Procedia Engineering, Vol. 10, 2651-2656, doi:10.1016/j.proeng.2011.04.442

[12] Conte, M.; Igartua, A. (2012). Study of PTFE composites tribological behavior, Wear, Vol. 296, No. 1-2, 568-574, doi:10.1016/j.wear.2012.08.015

[13] Xie, T.; Lin, Z. J.; Chen, G.; Jiao, M. H.; Yu, J. W.; Yin, Y. G.; Liu, K. (2010). Numerical analysis of influence of $\mathrm{Cu}$ particle content on thermal conductivity of PTFE-based composites, Metallic Functional Materials, Vol. 17, No. 2, 52-56, doi:10.13228/j.boyuan.issn1005$\underline{8192.2010 .02 .005}$

[14] Sorensen, B. (2015). High-velocity impact of encased Al/PTFE projectiles on structural aluminum armor, Procedia Engineering, Vol. 103, 569-576, doi:10.1016/j.proeng.2015.04.074 